Lisbon - Malacca Port Cities Twin Conferences 2019 / 2020

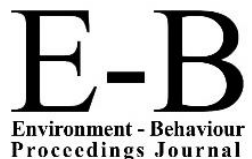

AicQoL2020Malacca

ASLI (Annual Serial Landmark International) Conferences on QoL2020

https://www.amerabra.org; https://fspu.uitm.edu.my/cebs; https://www.emasemasresources.com/

8th AMER International Conference on Quality of Life

Mahkota Hotel Melaka, Malacca, Malaysia, 18-19 Mar 2020

(Due to the Covid-19 lockdown, paper virtually presented on 25 Mar 2020)

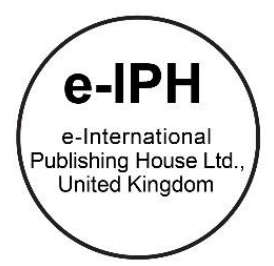

\title{
Factors Influencing Active Travel Mode to School for Primary School Children
}

\author{
Naimah Osman 1, Na'asah Nasrudin 2, Yusfida Ayu Abdullah ${ }^{2}$, Nurul Shakila Khalid ${ }^{2}$ \\ ${ }^{1}$ Center of Postgraduate Studies, \\ 2 Faculty of Architecture, Planning and Surveying, \\ Universiti Teknologi MARA, Shah Alam, Selangor, Malaysia
}

naimahosman@yahoo.com.my, naasa717@uitm.edu.my, yusfida@uitm.edu.my, shakilakhalid@uitm.edu.my

Tel: +60134361941

\begin{abstract}
Walking is a healthy way for children to explore their environment. However, nowadays, children prefer a passive mode of transport to commute to school. This paper aims to identify the factors that influence children to walk to school and evaluates the safety level of the children. This study, therefore, investigates children's preference to understand their perceptions on the choice to walk to school involving 100 primary school children in the Shah Alam City, Malaysia, through a case study method. Results indicated that distance to school, quality of the pedestrian facility and surrounding environment in a facility area affect the decision of children to walk to school.
\end{abstract}

Keywords: Active Travel Mode; Walking; Primary School Children

eISSN: 2398-4287 @ 2020. The Authors. Published for AMER ABRA cE-Bs by e-International Publishing House, Ltd., UK. This is an open access article under the CC BYNC-ND license (http://creativecommons.org/licenses/by-nc-nd/4.0/). Peer-review under responsibility of AMER (Association of Malaysian Environment-Behaviour Researchers), ABRA (Association of Behavioural Researchers on Asians) and cE-Bs (Centre for Environment-Behaviour Studies), Faculty of Architecture, Planning \& Surveying, Universiti Teknologi MARA, Malaysia.

DOI: https://doi.org/10.21834/e-bpj.v5i13.2089

\subsection{Introduction}

In Malaysia, using private vehicles to and from school is the most common type of mode of travel among primary school children during weekdays of a school year. In some areas, school children are living within a reasonable walking distance from school. For these children, active school transport (walking and cycling to or from school) can be such an excellent opportunity to accumulate physical activity regularly.

Several studies have emphasized that regular involvement in physical activity and active transportation can boost the social wellbeing and cognitive abilities of a child. Besides, daily physical activity may enhance cardio-metabolic health, better musculoskeletal health, improve in weight maintenance as well as increased psychosocial well-being for both children and adolescents (Lu, Sun, Gou, Liu, \& Zhang, 2019; Uddin, Mandic, \& Khan, 2019). This activity may improve the physical and mental health of the children (Yavuz Delice, Halit Ozen \& Amirnazmiafshar, 2015). Also, children who develop physical activity habits at a younger age are more likely to adopt this healthy lifestyle and benefits across their life span (Bürgi et al., 2011).

However, the percentage of students who walk to school has declined in recent decades (Jones \& Sliwa, 2016). As in Malaysia, not all children are willing to walk to or from school due to some constraints. A consistent decline in active school transportation among Malaysian children has drawn the attention of those concerned with children's health and well-being. Consequently, emerging literature has explored the factors that influence children to walk to school. Therefore, this study will identify factors considered by primary school

eISSN: 2398-4287 C 2020. The Authors. Published for AMER ABRA cE-Bs by e-International Publishing House, Ltd., UK. This is an open access article under the CC BYNC-ND license (http://creativecommons.org/licenses/by-nc-nd/4.0/). Peer-review under responsibility of AMER (Association of Malaysian Environment-Behaviour Researchers), ABRA (Association of Behavioural Researchers on Asians) and cE-Bs (Centre for Environment-Behaviour Studies), Faculty of Architecture, Planning \& Surveying, Universiti Teknologi MARA, Malaysia.

DOI: https://doi.org/10.21834/e-bpj.v5i13.2089 
children in practising active school transport (is it affected by sociodemographic characteristics, the built environment, and safety factors). This study conducted based on two objectives, which are to examine the standard school travel mode among primary school children as well as to identify the safety level of primary school children that walking to school.

\subsection{Literature Review}

The socio-ecological model is a behavioural theory useful in trying to understand the factors that influence the behaviour of physical activity (Vancampfort et al., 2019). Based on Tewahade et al. (2019), this model comprised of intrapersonal (demographic, psychological, cognitive and biological), interpersonal (social support), environmental (enjoyable scenery), and policy (regulations laws and rules) considerations. This section will briefly describe several factors considered in this study.

\subsection{Personal Factor}

Personal factor is the factor that significant to the respondent's background, where it is more related to the sociodemographic aspect. For instance, age, gender, employment status and vehicle ownership. The paper that was done by Raoniar, Das \& Banerjee (2019) reveals the findings from other studies that the girl was shown to be less likely to use Active School Travel compared to the boys and was more likely to be driven to school by family members.

\subsection{Built Environmental Factor}

The built environment defines as human-made elements of city design, including the distribution of office and residential spaces and transport infrastructures (roads, sidewalks and bike lanes), which increasingly recognized as a critical factor that can facilitate or impede transport on foot (Tewahade et al., 2019). He added that built environment features such as street accessibility, population density, mixed land use, proximity to school, and walkability, promote or hinder the use of active transport. Timperio, Veitch, \& Sahlqvist (2018) stated that street connectivity, the locality (rural or urban environment), and whether or not a trip involves crossing a busy street found to be associated with children engaged in active travel to school.

Several studies have recognized that built environmental factors have an essential role to play in promoting active school travel (walking to or from school). According to Mitra \& Buliung (2012), the availability of walking facilities (e.g., sidewalks, pedestrian crossings, and controlled traffic crossings) has reported as being correlated with active school travel.

The influence of built environments on walking activities can be even more significant. It is because children are more vulnerable to hazards and are subject to challenges in built environments. By considering the built environment, the mobility of walking activities is essential among children who have fewer modes of transport and, therefore, more likely to be affected by the surrounding environment (Lu et al., 2019). Several empirical studies on built environments and transportation walking indicate intricate patterns, with differences associations for some built environment characteristics.

\subsection{Safety Consideration}

Safety and security concerns have discouraged parents from promoting the use of sustainable transport. It is proved by the death rate for pedestrians in Malaysia, according to the statistics stated by (JKJR, 2018), was 562 deaths per year in which this figure made pedestrians the third-highest among road users involved in road accident fatality. More effort is needed to reduce pedestrian casualties while using the road.

\subsection{Methodology}

\subsection{School Selection}

Shah Alam city located within the district of Petaling and a portion of the Klang district in the state of Selangor. It covers an area of 290.3 $\mathrm{km}^{2}$, with a population of 617,149 as per the last census report in 2010 (Department of Statistics Malaysia, 2010). According to the Local Plan of Shah Alam City Council (Amendment 2), 2020 stated that the total number of primary schools distributed across Shah Alam City Council included 108 schools.

As a case study, three primary schools in Shah Alam selected for identifying factors considered by the school children aged 7 to 12 years old when they decide to walk to or from school. The schools located in the heart of several types of developments, including residential and commercial areas. The schools shortlisted from a list of potential schools in which the location of school must surround by the residential area. The three schools are Sekolah Kebangsaan Seksyen 7, Sekolah Kebangsaan Seksyen 18, and Sekolah Kebangsaan Padang Jawa. Also, these three selected schools feature diverse physical environmental characteristics and located in the urban area, which deals with heavy traffic volume during peak hours.

\subsection{Questionnaire Design}

This study used a method of questionnaire survey by distributing a set of questionnaires to 100 primary school children in three primary schools in Shah Alam City. In previous studies, researchers investigate children's preferences through their parents. This study was using a different approach from previous studies that used primary school children as targeted respondents instead of asking their parents to get the information on their children. The respondents that eligible to participate in the study are primary students who are walking to and from school only. 
Survey questions were developed based on the literature review from the previous studies. The questionnaire from (Yu \& Zhu, 2015) used as a reference. As a result, the questionnaire survey consists of several vital aspects to be studied, which divided into four sections, including demographic details, school trip details, built environment factors and safety factors. Categorical and Likert Scale questions are used to ask school children how much they agreed or disagreed with every argument included in the questionnaire survey using the scale of 1 (strongly disagree) to 5 (strongly agree). The survey was conducted by trained researchers who were assigned to distribute the questionnaires to the school children through a convenience sampling method.

Table 1. Factors Influencing Active Travel Mode Questionnaire

\begin{tabular}{cl}
\hline Category & Questions \\
\hline Demographic Details & $\begin{array}{l}\text { Age of student, gender (male, female), parent's occupation (government employee, private, self-employed, others), home address, } \\
\text { parent's vehicle ownership (yes, no) }\end{array}$ \\
\hline School Trip Details & $\begin{array}{l}\text { Preferences to walk, walking frequency to school in a week (rarely, sometimes, almost always, always), pedestrian size group (walk } \\
\text { alone, walking in a group), }\end{array}$ \\
\hline Built Environment & Sidewalk availability (some streets, available in all roads, no pedestrian facilities provided) \\
Factors & Sidewalks are: well maintained and clean, wide enough for two persons walking together, not separated from traffic by grass or trees, \\
& some paths not blocked by trash cans, power poles or cars, well shaded by trees, quiet (without much noise from cars, aeroplanes, \\
& factories, etc.), nice things to see, well-lit and school zones are well enforced (strongly disagree, disagree, undecided, agree and \\
& strongly agree) \\
\hline Safety and Security & $\begin{array}{l}\text { Get lost on the way to and from school, taken or hurt by a stranger, involved in an accident while walking to school and alert to other } \\
\text { Concern }\end{array}$ \\
\hline
\end{tabular}

\subsection{Limitations}

Throughout this study, few real-world interactions have contributed to certain limits. Due to time and resource constraints, there were only three out of 108 primary schools in Shah Alam selected for this study. Less significant, this study lacks quantitative and qualitative data, especially related to the surrounding environment of the school area. Physical elements such as road width and population density are an example of data that not considered in this study. Also, further associations between age, gender and parental employment status have not presented in the descriptive and qualitative research, which also needs to addressed in future studies.

\subsection{Findings}

\subsection{Respondent Background and Characteristics}

The descriptive statistics were obtained by analyzing the selected variables by looking into the frequency. The statistics revealed that the majority of the respondents involved $7 \%$ of 6 and 7 years old, $23 \%$ of 8 to 10 years old, and $70 \%$ of 11 and 12 years old. The study done by Raoniar, Das \& Banerjee (2019) found that parents with elderly children mostly allowed their children to walk to school compared to younger children. As above a certain age (11 to 12 years old), parents believed that their children could make safer decisions while using active travel mode. Also, based on the results, male students represent the highest respondents who participated in the survey, with $71 \%$, whereas the remaining (29\%) were female students. It supported by a study done by Raoniar et al. (2019) which reveals the findings that the girl shown to be less likely to use Active School Travel compared to the boys and most of them are driven to school by family members.

\subsection{Walking to School Trip Details}

Table 1 shows the Cross-Tabulation result for travelling distance and the frequency of children walking to school in a week. Travelling distance obtained by asking the student their home address and measured through the "Google Maps Walking Distance." One of the main determinants of active school travel is the distance from home to school.

Refer to Table 1; the statistics revealed that the majority of respondents, about $82 \%$ were living between $500 \mathrm{~m}$ to $1 \mathrm{~km}$ away from school. Then, it followed by $9 \%$ of respondents who lived more than $2 \mathrm{~km}$ away from school. Some students live less than $500 \mathrm{~m}$ and 1 $\mathrm{km}$ to $2 \mathrm{~km}$ from school, which recorded $6 \%$ and $3 \%$ of respondents, respectively. Based on this result, it can conclude that the ideal distance for primary students to walk is up to $1 \mathrm{~km}$ only. Those students who live more than $1 \mathrm{~km}$, yet the private vehicle such a car and motorcycle were the most preferred mode of transports to commute to school.

According to Development (2016), it stated that the minimum distance between the neighbourhood area and the school is less than $800 \mathrm{~m}$. Therefore, by referring to this statement, it meets the standard stated as it conforms to the guidelines. However, these results do not meet the standard stated by Perry (1929), which said that a limit of a one-quarter mile (402 $\mathrm{m}$ ) walking distance within the neighbourhood should be the catchment area for elementary schools. The standard is about inspiring and encouraging children to use active transport (walking) to school.

Frequency of children walking to school is another variable including in a school trip details that need to identify. Usually, those students who walk frequently have no problem walking thus, makes walking as their school travel mode. Based on Table 1, the results show that there is no significant difference between the four types of frequency.

Table 1 indicates that $29 \%$ and $24 \%$ of respondents were almost always and always walk to school in a week. They were only $22 \%$ of respondents that rarely walk to school. Thus, it can be inferred that all respondents that participated in the survey could be classified as active travellers. As mentioned by Dalton et al. (2011), in his study, active travellers are those who walked to or from school at least one day per week. 
Table 1. The Relationship between Travelling Distance from Home to School and the Frequency of Children Walking to School

\begin{tabular}{|c|c|c|c|c|c|}
\hline \multirow{2}{*}{ Travel Distance } & \multicolumn{4}{|c|}{ Walking Frequency (In a Week) } & \multirow{2}{*}{ Total $(\%)$} \\
\hline & rarely & sometimes & almost always & always & \\
\hline Less than 500 meters & 0 & 1 & 3 & 2 & 6 \\
\hline $500 \mathrm{~m}$ to $1 \mathrm{~km}$ & 18 & 20 & 24 & 20 & 82 \\
\hline $1 \mathrm{~km}$ to $2 \mathrm{~km}$ & 0 & 2 & 1 & 0 & 3 \\
\hline More than $2 \mathrm{~km}$ & 4 & 2 & 1 & 2 & 9 \\
\hline Total & 22 & 25 & 29 & 24 & 100 \\
\hline
\end{tabular}

This table also reveals that $24 \%$ of students living within 500 meters to $1 \mathrm{~km}$ away from school almost always walk to school. This finding proves that those students that frequently walk to school mostly comprised of those living within a distance of $500 \mathrm{~m}$ to $1 \mathrm{~km}$ from the school. However, after tested, there was no significant difference between the travel distance of children from home to school and the frequency of children walking to school in a week as Pearson Chi-Square showed that $X^{2}=9.213, d f=1 . N=100, p>0.01$.

Figure 1 shows the result of the pedestrian size group where indicates two types which are walking alone or in a group. The chart revealed that the majority of the respondents walk with a group with $77 \%$ of respondents compared to the students who walk alone, which recorded only $23 \%$. Walking in a group is classified as the respondent walk accompanied by their friends, parents or guardian.

\section{Pedestrian Size Group}

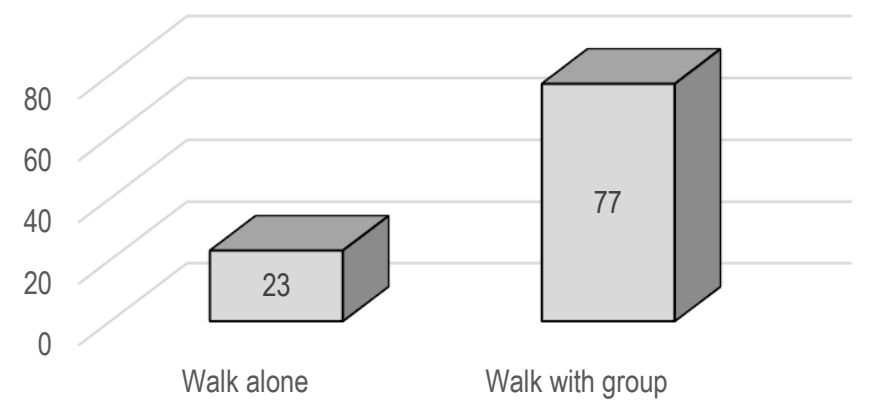

$\square$ Size Group

Fig. 1: Pedestrian Size Group

Figure 2 shows the reason why respondents walk to school. By referring to the preference of walking among the respondents, the majority of respondents agreed that walk could make them healthier (97\%). In terms of time, walking is saving their time (85\%) compared to another mode of transport (private vehicle and public transport) as they no need to spend their waiting time. $83 \%$ of respondents agreed that they love to walk rather than using a private car or motorcycle as walking is one of the transportation modes that exposed them to the surrounding environment. However, there were $57 \%$ of respondents disagreed with the statement stated that parents ask them to walk. This result proves that they walk because of their willingness to do it, not because of other's influence (parents).

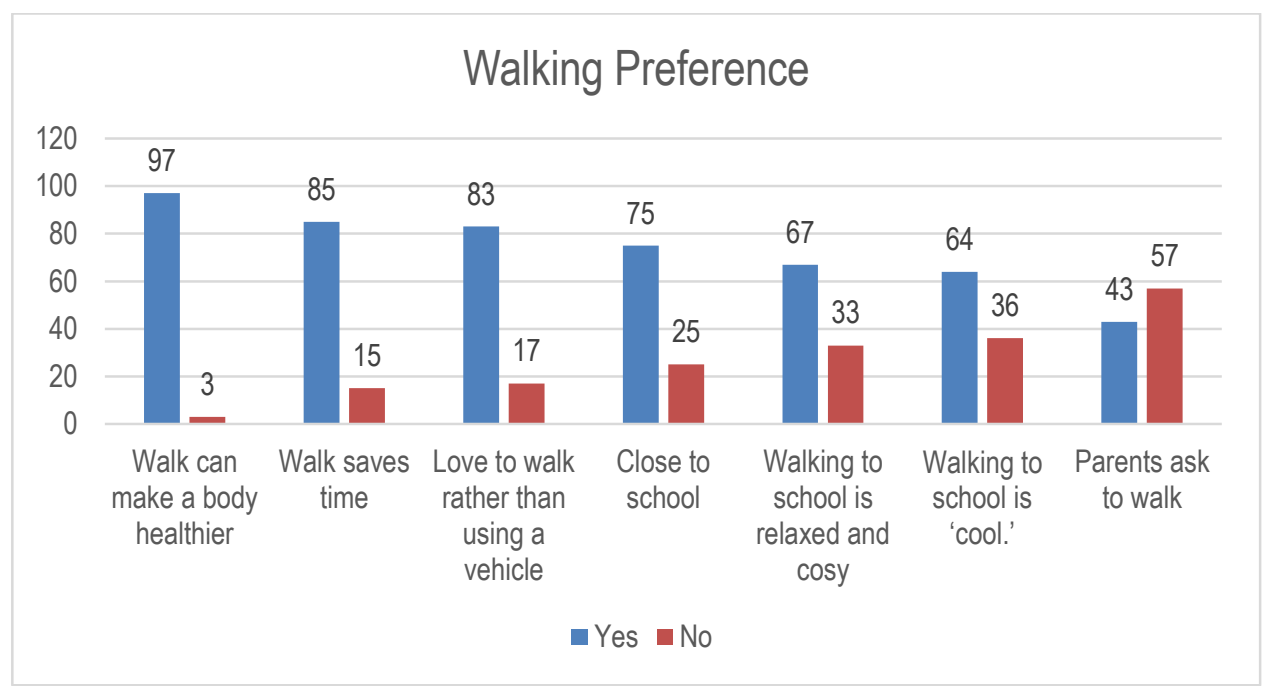

Fig. 2: Walking Preference 


\subsection{Built Environmental Factors}

According to Dalton et al. (2011), the availability and quality of sidewalks, walking environment, and street accessibility correlated with more frequent active children's transportation.

For the sidewalk availability in three schools selected, the data represents that $51 \%$ of respondents agreed that there is sidewalk provided on some streets outside the school area, and only $9 \%$ of them agreed that the provision of pedestrian facilities is available on all roads outside the school area. However, $12 \%$ of respondents admitted to saying that there is no pedestrian facility provided outside their school area.
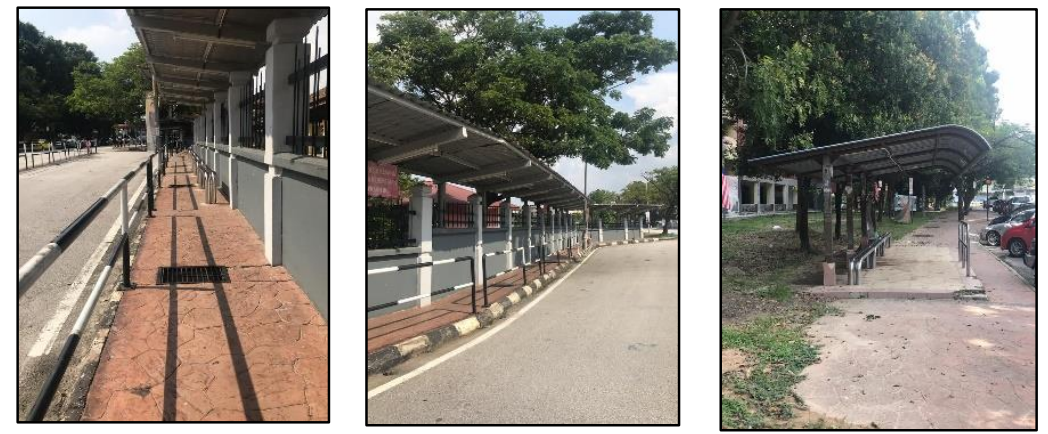

Fig. 3: Pedestrian Facilities in Sekolah Kebangsaan Seksyen 7

For the second aspect, which is the quality of the sidewalk, table 2 indicated the result for each characteristic asked. The majority of respondents had chosen to agree and very agree with all the statements asked in the questionnaire. For the first point, sidewalks are well maintained and clean, which recorded the Mean $=3.79 .21 \%$ and $50 \%$ of respondents answered agreed and strongly agreed respectively with the statements. It indicated that the existing condition of the sidewalk facilities outside their school area is well maintained and clean; thus, respondents were satisfied. Ample space is an important criterion that needs to concern to allow children to have a company instead of walking alone. The width of the sidewalk also recorded a high number of respondents who agreed, with the mean recorded as 4.48. It proves that the path is enough for two persons or more to walk together. The third point, which is the separation from traffic, the result reported a low mean $(M=2.80)$, which proves that the separation discontinuously provided along the way from home to school. The last point mentioned regarding the obstacles that blocked the sidewalks, which recorded the mean of 4.17. The majority of respondents agreed that the walking path not blocked by other constraints (e.g. trash cans, power poles or cars) where is no interruption along the way from home to school (refer to Figure 3).

\begin{tabular}{lccccccc} 
Table 2. Sidewalk Quality & & & \\
\hline \multicolumn{1}{c}{ Characteristic } & 1 & 2 & 3 & 4 & 5 & Mean \\
\hline Sidewalks are well maintained and clean & 13 & 16 & - & 21 & 50 & 3.79 \\
Sidewalks are wide enough for two persons walking together & 3 & 4 & - & 28 & 65 & 4.48 \\
Sidewalks are not separated from traffic by grass or trees & 17 & 21 & 7 & 35 & 20 & 2.80 \\
Some sidewalks not blocked by trash cans, power poles or cars & 5 & 6 & 8 & 29 & 52 & 4.17 \\
\hline
\end{tabular}

The third aspect is the walking environment. Table 3 shows the majority of respondents disagreed with most of the statements asked. For the first statement regarding the covered pedestrian, the mean recorded was 2.87 . In many areas that facilitate with pedestrian facilities, there is no trees and covered pedestrian walkway to protect a student that walking through it from hot and raining. Besides, the majority of respondents were strongly disagreed and disagreed to say that outside their school area is quiet without so much noise from the surrounding, with the mean recorded only 1.86. As mentioned in the previous section, the schools selected deal with a high volume of traffic during peak hours, which contributes to the noise. The next point, which is the view of the walking environment, the mean recorded is low, which is 2.63 . The result is due to the location of the schools situated in the residential and commercial development areas. In terms of lighting facilities, the respondents were satisfied $(M=3.92)$, with the majority of the respondents agreed and strongly agreed with the percentage recorded $19 \%$ and $67 \%$, respectively. Overall, for this aspect, the highest mean recorded by the enforcement within the school zones with mean recorded as 4.04 . This result proves that the security guards play a functional role in controlling the traffic outside the school area and the student movement while crossing the road, especially during peak hours (start and end of school sessions).

Table 3. Overall Walking Environment

\begin{tabular}{lllllll}
\hline \multicolumn{1}{c}{ Characteristic } & 1 & 2 & 3 & 4 & 5 & Mean \\
\hline Trees well shade it & 34 & 14 & 7 & 21 & 24 & 2.87 \\
It is quiet (without much noise from cars, aeroplanes, factories, etc.) & 61 & 18 & 5 & 6 & 10 & 1.86 \\
There are nice things to see & 49 & 5 & 6 & 14 & 26 & 2.63 \\
Streets are well lit & 19 & 3 & 2 & 19 & 57 & 3.92 \\
School zones are well enforced & 15 & 3 & 3 & 21 & 58 & 4.04 \\
\hline
\end{tabular}

$* 1=$ strongly disagree, $2=$ disagree, $3=$ undecided, $4=$ agree, $5=$ strongly agree 


\subsection{Safety and Security Concern}

The safety and security aspect is the last factor focused on this study. Table 4 indicated that most of the characteristics under the safety factor recorded a lower mean, which proves that the study area prioritizes the safety aspect. The result reveals the majority of respondents disagreed with the statement of getting lost in the journey to and from school $(M=1.40)$. This result proves that the routes are direct and not confusing. $84 \%$ and $8 \%$ of respondents strongly disagreed and disagreed, respectively, with the statement of getting interference from strangers with the mean recorded as 1.34 , which proves that the study area is safe from criminal cases.

Also, the majority of respondents disagreed with the statement regarding accident cases with the mean recorded as 1.15 . 95\% of respondents agreed that they always be alert with the other vehicles when walking on pedestrian paths. It showed that students always prioritize safety throughout their journey to school.

Table 4. Safety and Security Concern

\begin{tabular}{lllllll}
\hline \multicolumn{1}{c}{ Characteristic } & 1 & 2 & 3 & 4 & 5 & Mean \\
\hline Get lost on the way to and from school & 76 & 18 & - & 2 & 4 & 1.40 \\
Taken or hurt by a stranger & 84 & 8 & 2 & 2 & 4 & 1.34 \\
Had been involved in an accident while walking to school & 89 & 9 & 1 & - & 1 & 1.15 \\
Always be alert to other vehicles when walking on pedestrian paths & 5 & - & - & 5 & 90 & 4.75 \\
\hline
\end{tabular}

*1=strongly disagree, $2=$ disagree, $3=$ undecided, 4=agree, 5=strongly agree

\subsection{Discussion}

The study finding reveals that the elder children (aged 11 and 12 years old) are more exposed to active transport compared to younger children (aged 7 to 10 years old). As the age of children grows, parents see them as increasingly confident and able to meet their own needs (Raoniar, Das \& Banerjee, 2019). Yeung, Wearing, \& Hills (2008), in their study, highlighted the increasing number in the usage of active travel with the increase in age.

Besides, the finding indicates that $500 \mathrm{~m}$ to $1 \mathrm{~km}$ is an ideal distance for primary school children to walk. According to Singh \& Vasudevan (2018), schools located in the area of the home usually favoured by parents. There was a lack of time for the parents to escort their children to far-off schools. Therefore, parents allowed their children to self-commuting (walking) to and from school as the distance from home to school closed. Otherwise, they will use a private vehicle as their school mode of transportation. Besides, parents were less likely to choose an active transport mode when the school situated at far distance $(>1 \mathrm{~km})$ and parents usually have strong preferences for certain types of transport (school bus) (Raoniar et al., 2019). Based on the findings that have discovered, it clearly shows that distance influences active travel mode to school among primary school children. As has been said by Su et al. (2013), distance to school is a significant barrier to walking as the distance from home to school increased. There also decreased the probability of going to school. Also, those children who frequently walk usually will make the walk as their habit, including walking to or from school every day.

The finding suggests that distance to school, quality of the pedestrian facility and surrounding environment in a facility area prohibit children's active commuting to school. It also has an important implication on the safe walking environment and child-friendly urban design.

\subsection{Conclusion \& Recommendations}

There are very few active travels to school studies have been conducted in Malaysia. To the best of author's knowledge, this is the first research to understand the factors influencing walking to school among primary school children conducted in Malaysia. This result suggests that the significant factors for mode choice are age, gender, distance, the built environment factor and safety consideration. The relationship between active travel mode (walking) and all these factors was mostly consistent with previous studies conducted.

It is essential to understand the factors that influence children walking to school as it may contribute to the development of effective interventions, which, in turn, may improve the school children's health. By understanding, all the factors that influence active travel mode among primary school children may support interventions to increase rates of walking to school, and it automatically might promote their physical activity. Besides, these interventions can also contribute to the development of neighbourhoods that are more pedestrianfriendly and encourage awareness of supportive environments.

As an effort to increase the level of active transport among primary school children, state and local health promotion initiatives must be initiated. It includes a collaborative effort between governmental and non-governmental agencies where it promotes direct interest, especially for the safety, environment, and health of the school children. Apart from upgrading an existing pedestrian facility, policymakers also should be aware to facilitate active commuting through social initiatives in local communities. For example, school siting policies and guidelines specifically for school walk can also be implemented.

This study contributed crucial knowledge in depth regarding the impact of built environments and safety concerns on the children's walking to school behaviour. Findings that have discovered from this study have important implications in future interventions as it targeting the promotion of walking to school among primary school children. This study was focusing on the urban area; thus, future research should include rural communities to understand the significance. 


\section{Acknowledgement}

This study funded by the Tabung Amanah Pembangunan Akademik (TAPA), Faculty of Architecture, Planning and Surveying, Universiti Teknologi Mara (UiTM) Shah Alam.

\section{References}

Bürgi, F., Meyer, U., Granacher, U., Schindler, C., Marques-Vidal, P., Kriemler, S., \& Puder, J. J. (2011). Relationship of physical activity with motor skills, aerobic fitness and body fat in preschool children: A cross-sectional and longitudinal study (Ballabeina). International Journal of Obesity. https://doi.org/10.1038/ijo.2011.54

Dalton, M. A., Longacre, M. R., Drake, K. M., Gibson, L., Adachi-Mejia, A. M., Swain, K., .. Owens, P. M. (2011). Built environment predictors of active travel to school among rural adolescents. American Journal of Preventive Medicine, 40(3), 312-319. https://doi.org/10.1016/j.amepre.2010.11.008

Development, E. C. (2016). Planning Guidelines for Educational Facilities. (February).

JKJR. (2018). Buku Statistik Keselamatan. Road Safety Department of Malaysia, (april), 5.

Jones, S. E., \& Sliwa, S. (2016). School factors associated with the percentage of students who walk or bike to school, school health policies and practices study, 2014 Preventing Chronic Disease, 13(5), 1-9. https://doi.org/10.5888/pcd13.150573

Lu, Y., Sun, G., Gou, Z., Liu, Y., \& Zhang, X. (2019). A dose-response effect between built environment characteristics and transport walking for youths. Journal of Transport and Health, 14(January). https://doi.org/10.1016/j.jth.2019.100616

Mitra, R., \& Buliung, R. N. (2012). Built environment correlates of active school transportation: Neighborhood and the modifiable areal unit problem. Journal of Transport Geography, 20(1), 51-61. https://doi.org/10.1016/j.jtrangeo.2011.07.009

Perry, C. (1929). The Neighborhood Unit (1929). The Regional Plan of New York and Its Environs. Retrieved from http://www.sethspielman.org/courses/geog3612/readings/Perry.PDF

Rahul Raoniar, Trinayan Das, Arunabha Banerjee, A. K. M. (2019). The Parents' Role in School Mode Choice for their Children: A Case Study in Guwahati. Journal of the Eastern Asia Society for Transportation Studies, 13, 775-794. https://doi.org/10.11175/easts.13.775

Singh, N., \& Vasudevan, V. (2018). Understanding school trip mode choice - The case of Kanpur (India). Journal of Transport Geography, 66(January), 283-290. https://doi.org/10.1016/j.jtrangeo.2017.12.007

Su, J. G., Jerrett, M., McConnell, R., Berhane, K., Dunton, G., Shankardass, K., ... Wolch, J. (2013). Factors influencing whether children walk to school. Health and Place, 22, 153-161. https://doi.org/10.1016/j.healthplace.2013.03.011

Tewahade, S., Li, K., Goldstein, R. B., Haynie, D., lannotti, R. J., \& Simons-Morton, B. (2019). Association between the built environment and active transportation among U.S. adolescents. Journal of Transport and Health, 15(August), 100629. https://doi.org/10.1016/j.jth.2019.100629

Timperio, A., Veitch, J., \& Sahlqvist, S. (2018). Built and Physical Environment Correlates of Active Transportation. In Children's Active Transportation. https://doi.org/10.1016/b978-0-12-811931-0.00010-7

Uddin, R., Mandic, S., \& Khan, A. (2019). Active commuting to and from school among 106,605 adolescents in 27 Asia-Pacific countries. Journal of Transport and Health, 15(August), 100637. https://doi.org/10.1016/j.jth.2019.100637

Vancampfort, D., Van Damme, T., Firth, J., Smith, L., Stubbs, B., Rosenbaum, S., ... Koyanagi, A. (2019). Correlates of physical activity among 142,118 adolescents aged 12-15 years from 48 low- and middle-income countries. Preventive Medicine, 127(August), 105819. https://doi.org/10.1016/j.ypmed.2019.105819

Yavuz Delice, Halit Ozen, \& Amirnazmiafshar, E. (2015). International Conference on Transportation and Development. (2003), 289-298. Retrieved from http://www.asceictd.org/

Yeung, J., Wearing, S., \& Hills, A. P. (2008). Child transport practices and perceived barriers in active commuting to school. Transportation Research Part A: Policy and Practice, 42(6), 895-900. https://doi.org/10.1016/j.tra.2007.12.007

Yu, C. Y., \& Zhu, X. (2015). Impacts of Residential Self-Selection and Built Environments on Children's Walking-to-School Behaviors. Environment and Behavior, 47(3), 268-287. https://doi.org/10.1177/0013916513500959 